\title{
EFECTOS DEL EMBARGO Y REALIZACION DE DERECHOS SOCIALES EN UNA SOCIEDAD DE PERSONAS
}

\author{
Alberto Viada Lozano \\ Profesor de Derecho comercial \\ Universidad Católica del Norte-Coquimbo
}

En el ejemplar del año 6 - 1999 de esta Revista de Derecho, el profesor de la Escuela de Derecho de la Universidad Católica del Norte - Sede Coquimbo, don Roberto Medina Infante, presentó un trabajo de investigación titulado: "Embargo sobre derechos sociales", (págs. 157 a 166, ambas inclusive), en el que llega a las siguientes conclusiones: "Primero: No es embargable el aporte introducido por el socio en la sociedad, una vez que se hayan cumplido con los requisitos legales del caso; Segundo: En las sociedades civiles pueden embargarse las asignaciones que se hagan al deudor por cuenta de los beneficios sociales o de sus aportes o acciones; Tercero: En las sociedades comerciales se puede solicitar la retención de la parte de interés que el deudor tuviera en ellas para percibirla al tiempo de la división social y, además, embargar las asignaciones que se hagan al deudor por cuenta de beneficios sociales o de sus aportes o acciones; y Cuarto: En todos los casos, el acreedor puede rematar sus derechos y el tercero que subaste adquirirá el crédito con las limitaciones indicadas".

Al respecto quisiera dilucidar algunos matices que encuentro confundidos, tanto en el trabajo referido precedentemente como en aquéllos citados por el colega Medina, (Gabriel Palma Rogers, "Derecho Comercial", Imprenta Chile año 1.928; Arturo Alessandri Rodríguez y Manuel Somarriva Undurraga, compendio preparado por Antonio Vodanovic II., Editorial Nascimento, años 1939-42, Tomo IV, y Enrique Munita Becerra, informe de derecho publicado en la Revista de Derecho y Jurisprudencia, tomo 57, Secc. Derecho, págs. 89 a 103).

\section{I.- DELIMITACIÓN DEL TEMA}

Aclaro que mis opiniones se refieren exclusivamente al embargo de los derechos de un socio en una sociedad de personas, esto es: colectivas, de responsabilidad limitada, o mixtas, y de éstas sólo respecto de los derechos de los socios gestores de las sociedades en comandita, sean simples o por acciones. Ello, porque no pareciera que hubiera ninguna duda o discusión sobre que los derechos de los socios capitalistas, accionistas de sociedades anónimas o en comandita por acciones, o comanditarios de 
las en comandita simples, son libremente embargables y vendibles, sucediendo el adquirente de ellos en todos los derechos y obligaciones del socio deudor.

Otro aspecto en que no me propongo ahondar más, puesto que no existe ni siquiera un matiz de discrepancia sobre ello, es que no es embargable el aporte introducido por un socio en la sociedad. Obviamente que se debe entender introducido en la sociedad una vez efectuada la tradición del bien aportado, que en algunos casos es solemne, habiendo cumplido todos los requisitos legales del caso. Al respecto, existen las disposiciones legales expresas de los artículos 2.096 del Código Civil y 380 del Código de Comercio. $\mathrm{Y}$, aunque el legislador no hubiera dictado estas normas especiales, siempre cabría llegar a la misma conclusión, puesto que dichos bienes, desde el momento que se efectuó válidamente la tradición a la sociedad, dejaron de pertenecer al socio deudor y pasaron a ser de propiedad de la sociedad, "persona jurídica distinta de los socios individualmente considerados". Naturalmente que siempre quedarán a salvo las acciones reales que el acreedor del socio tuviere para ejercer su derecho real de prenda o hipoteca sobre algún bien aportado, pero ello no será materia específicamente tratada en este ensayo, como tampoco las muy infrecuentes acciones indirectas o subsidiarias contempladas en el artículo 2.094 del Código Civil.

No pretendo distinguir entre sociedades civiles o comerciales. Este trabajo se ciñe, precisamente, al embargo de los derechos de un socio de una sociedad de personas, sea civil o comercial, y los efectos que pueden derivarse de dicho embargo. Pero creo necesario referirme a la retención, que el colega Medina concluye como privativa de las sociedades comerciales, y al embargo de asignaciones que se hagan al socio deudor por cuenta de los beneficios sociales o de sus aportes o acciones, que hace aplicables a todo tipo de sociedad de personas, civiles o comerciales.

\section{II.- RETENCIÓN}

El artículo 380 del Código de Comercio, en lo pertinente, dispone: a "los acreedores personales de un socio... les será permitido solicitar la retención de la parte de interés que en ella tuviere para percibirla al tiempo de la división social". Y el hecho de que esta facultad que la ley concede a los acreedores personales de un socio venga precedida, en el mismo artículo, de la prohibición de embargar durante la sociedad el aporte que él hubiere introducido, ha motivado que se confundan o mezclen el embargo con la retención.

El embargo, institución típica del procedimiento ejecutivo o del cumplimiento de las resoluciones judiciales, está descrito en el artículo 450 del Código de Procedimiento Civil como "la entrega real o simbólica de los bienes al depositario que se designe, aunque éste deje la especie en poder del mismo deudor". En cambio, la retención es la 
medida precautoria señalada en el № $3^{\circ}$ del artículo 290 del mismo Código, susceptible de obtenerse en todo tipo de juicio y en cualquiera etapa de su tramitación, incluso como medida prejudicial, y que el artículo 295 de dicho cuerpo legal autoriza, al igual que otros, "en los demás casos determinados por la ley", entre los que podemos contar obviamente el del artículo 380 del Código de Comercio, ya transcrito. Y corrobora esta distinción el contenido de los incisos primero y segundo del numero $3^{\circ}$ del artículo 235 del Código de Procedimiento Civil, al referirse al cumplimiento de una sentencia que mande pagar una suma de dinero, puesto que en el primer caso "se dispondrá previamente la realización de los bienes que estén garantizando el resultado de la acción de conformidad al Título $\mathrm{V}$ del Libro II", o sea: las medidas precautorias, entre las cuales se cuenta la retención. En cambio, en el inciso segundo citado la ley se pone en el caso que no existan medidas precautorias -retención -, disponiendo que entonces "se procederá a embargar y a enajenar bienes suficientes de la parte vencida de acuerdo con las reglas del procedimiento de apremio".

Lamentablemente, a diferencia de lo que ocurre con el embargo, la ley no define ni describe lo que debe entenderse por retención, por lo que me permito recurrir al efecto a don Fernando Alessandri Rodríguez ("Derecho Procesal Civil", Edit. Nascimento, pág. 242), quien señala lo siguiente: "Por la retención se da orden a la persona que tiene la cosa de retenerla y no entregarla sin orden del tribunal". Para el acreedor esta retención, además de la ventaja de poder obtenerla antes de que se dicte sentencia favorable en el juicio, e incluso antes de iniciar el juicio como medida prejudicial, goza de una preferencia como crédito de segunda clase, reconocido y entregado por el artículo 2.475 del Código Civil "a lo dispuesto en el Código de Comercio". Al respecto es ilustrativo transcribir parte del artículo 149 de la actual Ley de Quiebras ( $N^{2} 18.175$ ), que, al hablar de la graduación de créditos y su pago, dispone: "Los acreedores de segunda clase, incluidos los que gocen del derecho de retención judicialmente declarado, podrán ser pagados sin aguardar las resultas de la quiebra, siempre que se asegure lo necesario para pagar los créditos de la primera clase si los demás bienes de la masa no parecieren suficientes para satisfacerlos" ; agregando en su inciso segundo: "Con tal objeto, dichos acreedores podrán iniciar, ante el tribunal que conozca de la quiebra, los procedimientos que correspondan, o continuar ante él los ya iniciados en otros juzgados, si prefirieren no dejar en manos del síndico la realización de los bienes gravados".

En todo caso, queda absolutamente claro que la retención de que habla el artículo 380 del Código de Comercio, es algo totalmente distinto que el embargo de los derechos de un socio en una sociedad de personas, que pretende ser el objeto principal de este ensayo. 


\section{III.- EMBARGO DE ASIGNACIONES}

A ello se refiere el artículo 2.096 del Código Civil (aplicable a las sociedades comerciales en virtud de lo establecido en el artículo 96 del Código de Comercio), que, en lo pertinente dispone: "Los acreedores de un socio... podrán también pedir que se embarguen a su favor las asignaciones que se hagan a su deudor por cuenta de beneficios sociales o de sus aportes o acciones".

Es usual actualmente que las sociedades practiquen balances periódicos, por lo menos anualmente, y que de sus resultados, se repartan entre los socios las utilidades en proporción de sus derechos en la sociedad. Ello es incluso legalmente obligatorio en las sociedades anónimas, en las que estas asignaciones toman el nombre de dividendos. En las sociedades de personas, si no está establecido en los estatutos, la ley dispone que la distribución de beneficios debe hacerse normalmente "a prorrata de los valores que cada socio ha puesto en el fondo social" y "si uno de los socios contribuyere solamente con su industria, servicio o trabajo, y no hubiere estipulación que determine su cuota en los beneficios sociales, se fijará esta cuota en caso necesario por el juez" (Arts. 2.068 y 2.069 del Código Civil), y respecto de las sociedades comerciales las normas legales son las siguientes: "Los socios capitalistas dividirán entre sí las ganancias y pérdidas en la forma que se hubiere estipulado. A falta de estipulación, las dividirán a prorrata de sus respectivos aportes", y "en cuanto a las ganancias y pérdidas correspondientes al socio industrial, se estará a lo que se hubiere estipulado en el contrato; y no habiendo estipulación, el socio industrial llevará en las ganancias una cuota igual a la que corresponda al aporte más módico, sin soportar parte alguna en las pérdidas", (Arts. 382 y 383 del Código de Comercio).

También sabemos que el artículo 352 № $8^{ }$del Código de Comercio, dentro de las solemnidades de constitución de una sociedad de personas comercial, dispone que la escritura pública "deberá expresar:... $8^{\circ}$ La cantidad que puede tomar anualmente cada socio para sus gastos particulares". Actualmente, para evitar verse constreñidos por un acuerdo contractual rígido, se suele cumplir con esta exigencia legal señalando que dicha cantidad privativa de cada socio la acordarán anualmente todos los socios o solamente el o los administradores.

Por último, si así se hubiere estipulado en la escritura pública de constitución de la sociedad, conforme al N $9^{2}$ del artículo 352 del Código de Comercio, o lo acordaren unánimemente los socios durante la liquidación, pueden existir repartos parciales de beneficios a los socios durante el proceso de liquidación de la sociedad.

Pues bien, a todas estas asignaciones se refiere el artículo 2.096 transcrito, que los acreedores personales de un socio pueden también embargar. Estimo incluso que, aunque conveniente, no era indispensable que la ley lo estableciera expresamente, 
puesto que tales asignaciones, están incorporadas en el patrimonio personal del socio deudor $y$, por ende, pueden ser embargadas dentro del denominado "derecho de prenda general de los acreedores".

En todo caso, opino que este embargo es especial y distinto del embargo de los derechos de un socio en una sociedad de personas que, repito, es el objeto específico y principal de este ensayo.

\section{IV.- EMBARGO DE DERECHOS SOCIALES}

Con las aclaraciones anteriores, paso directamente al tema principal que nos ocupa, esto es: la procedencia de embargar los derechos sociales de un socio por un acreedor personal de él y los efectos que de ello derivan.

Para empezar, como fue el estímulo que provocó este ensayo, vuelvo a referirme a la conclusión cuarta del trabajo del profesor Roberto Medina Infante, transcrita al inicio de mis comentarios. Coincido en que el acreedor puede embargar y llevar a remate los derechos sociales de su deudor personal, pero discrepo en que el que adquiera dichos derechos sociales en el remate lo haga con las limitaciones de la retención y embargo de asignaciones, a que se refiere en sus conclusiones segunda y tercera. Creo que, en los acápites precedentes de este ensayo, ha quedado establecido suficientemente que se trata de temas distintos, independientes e incluso válidamente coexistentes. El acreedor, en cualquier estado del juicio e incluso antes de su inicio, puede solicitar y obtener la medida precautoria de "retención de la parte de interés que en la sociedad tuviere su deudor socio, para percibirla al tiempo de la división social". El mismo acreedor, siempre que cuente con un título ejecutivo, que puede ser la sentencia definitiva firme o ejecutoriada en que se reconozca su crédito contra el deudor socio, puede solicitar y obtener el embargo de todos los derechos del deudor socio en la sociedad, o "también pedir que se embarguen a su favor las asignaciones que se hagan a su deudor por cuenta de beneficios sociales o de sus aportes o acciones".

Entonces, para establecer la procedencia del embargo de todos los derechos sociales de un deudor socio de una sociedad de personas, es decir, su calidad de socio, me vestiré con ropajes ajenos y transcribiré las partes pertinentes del informe de derecho del profesor Enrique Munita Becerra, que, como se dijo al inicio, también sirvió de fundamento al trabajo del colega Roberto Medina Infante. Dichos argumentos, publicados en la Revista de Derecho y Jurisprudencia, Tomo LVII, año 1960, Sección Derecho, páginas 89 a 103, ambas inclusive, son los siguientes: "Con respecto al primer punto, o sea, a la inembargabilidad, materia de este informe, se debe tener presente que esta situación de un bien es excepcional o de derecho estricto, pues todos los bienes de un deudor responden de sus obligaciones, exceptuándose solamente los no 
embargables (artículo 2.465 del Código Civil). De suerte que para tener un bien la calidad jurídica de "inembargable" debe estar expresamente exceptuado por medio de una ley...". "En consecuencia, se debe descartar - siendo ello un principio indiscutido e indiscutible - que una inembargabilidad pudiera emanar de interpretaciones legales, de analogías, de aplicación de preceptos por extensión y menos aún, de opiniones de tratadistas o de resoluciones de tribunales que no se basen en textos claros, explícitos y terminantes de la ley expresa".

"El derecho social de un socio en la sociedad de que forma parte, nace desde la constitución misma de ésta. Es un bien que él incorpora a su patrimonio, recae en forma ideal sobre el conjunto del patrimonio social de manera alícuota e indeterminada, no se puede ejercitar sobre uno o más bienes específicos de dicho patrimonio, como sucede o puede suceder en la comunidad...". "Si es un derecho ideal, no por ello deja de ser tangible, claro, preciso y valorable. Es un derecho mueble, sometido al régimen jurídico de tal, transmisible, transferible $y$, como se demostrará, embargable; sin perjuicio que, según el tipo de sociedad y según, a veces, la estipulación de las partes, su trasmisión y su transferencia sean más o menos amplias o liberadas o reglamentadas, pero jamás "prohibidas", pues no se trata de un derecho "personalísimo" como el uso y la habitación, mencionados expresamente como "inembargables", debido a ese carácter, en los artículos 1.618, № 9 del Código Civil y 445, № 15 del Código de Procedimiento Civil...". (Al respecto creo conveniente aclarar que la aparente prohibición para los socios de "ceder a cualquier título su interés en la sociedad", contemplada en el Nํำ del artículo 404 del Código de Comercio, no es tal, puesto que dicha cesión sería plenamente válida contando con la previa autorización de todos los socios, como lo aclara el inciso segundo del mismo $N^{2} 3^{\circ}$ citado, por lo que en realidad solamente se está estableciendo el requisito o condición del consentimiento de los socios, pero no prohibiendo la cesión voluntaria).

"En consecuencia, este bien patrimonial del socio queda comprendido en el llamado "derecho de prenda general" de sus acreedores, cuya base legal se encuentra en el artículo 2.465 del Código Civil. No hay ninguna disposición o texto de ley que declare su inembargabilidad y, por tanto, queda sujeto a las reglas generales sobre esta materia".

Al final de su informe en derecho, entre otras, el profesor Enrique Munita Becerra llega a las siguientes conclusiones: "Todo bien es embargable, salvo que una ley expresa lo excluya de tal carácter $y$, por tanto, no puede determinarse la inembargabilidad por interpretación, extensión o analogía de disposiciones legales hechas por el tribunal y menos deducirla de opiniones de tratadistas..."; y: "El acreedor investido de un título ejecutivo puede embargar y llegar, naturalmente, a subastar el derecho social del socio deudor...". 
Adhiero plenamente a las conclusiones transcritas precedentemente.

Ahora bien, el ministro de fe encargado de la diligencia de embargo deberá cumplir con todas las exigencias procesales establecidas en los artículos 450 y 455 del Código de Procedimiento Civil. Para los efectos de publicidad del embargo, sólo respecto de aquellas sociedades que requieren de inscripción en el Registro de Comercio, estimo que también el ministro de fe podría requerir del Conservador de Comercio la subinscripción o anotación del embargo al margen de la inscripción social, conforme a lo dispuesto en el artículo 40 del Reglamento para el Registro de Comercio y Título VIII del Reglamento del Registro Conservatorio de Bienes Raíces. Incluso sería conveniente, ("lo que abunda no daña"), que también se comunicara el embargo al o a los administradores de la sociedad, si el socio deudor no lo fuere, por carta certificada.

\section{V.- EFECTOS DEL EMBARGO DE LOS DERECHOS SOCIALES DE UN DEUDOR EN UNA SOCIEDAD DE PERSONAS}

a) En primer lugar, desde el momento mismo del embargo los derechos del deudor socio dejan de estar en el comercio humano; su enajenación adolecería de objeto ilícito, a menos que el juez lo autorice o el acreedor consienta en ello (Art. 1.464 $^{0} 3^{\circ}$ del Código Civil). Ni siquiera pueden ser objeto de una promesa de celebrar un contrato que pudiere significar la enajenación de todo o parte de dichos derechos sociales (Art. 1.554 № 2 del Código Civil).

b) Obviamente que el deudor socio puede hacer uso del derecho que le confiere el artículo 457 del Código de Procedimiento Civil esto es: "Puede el deudor en cualquier estado del juicio substituir el embargo, consignando una cantidad suficiente para el pago de la deuda y costas...".

c) Por último, conforme al artículo 490 del Código de Procedimiento Civil, "Antes de verificarse el remate, puede el deudor libertar sus bienes pagando la deuda y costas". Y también puede hacer este pago, subrogándose en los derechos del acreedor, cualquier tercero distinto del deudor, incluyendo naturalmente uno o varios de los consocios o la misma sociedad de que forma parte, puesto que se trata de "una persona jurídica, distinta de los socios individualmente considerados".

\section{VI.- REALIZACION DE LOS DERECHOS SOCIALES EMBARGADOS.}

Si no se hubiere ejercido alguno de los derechos de substitución o pago, a los que nos hemos referido precedentemente, y el deudor socio no hubiere opuesto excepciones a la ejecución, conforme al artículo 472 del Código de Procedimiento Civil: "se omitirá la sentencia y bastará el mandamiento de ejecución para que el acreedor pueda perseguir la realización de los bienes embargados y el pago". Norma similar contempla 
el artículo 235 del mismo Código para el caso de que la parte vencida no se hubiere opuesto al cumplimiento de la sentencia solicitada conforme al artículo 233, en cuyo caso, si no hay bienes que estuvieren asegurando el resultado de la acción mediante medidas precautorias, "se procederá a embargar y a enajenar bienes suficientes de la parte vencida de acuerdo con las reglas del procedimiento de apremio, sin necesidad de requerimiento". Y si los derechos sociales del deudor estuvieran afectos a una medida precautoria, "se dispondrá previamente la realización de los bienes que estén garantizando el resultado de la acción..."

En cambio, si la parte vencida se hubiere opuesto al cumplimiento de la sentencia deberá esperarse que quede firme o ejecutoriada, o cause ejecutoria, la sentencia interlocutoria que resuelva el incidente rechazando la oposición. $Y$ si hubiere oposición a la ejecución, también deberá esperarse que se dicte la sentencia definitiva que falle el juicio ejecutivo, que rechace las excepciones en que se hubiere fundado la oposición y mande seguir adelante la ejecución. Esta sentencia definitiva causa ejecutoria desde que se notifica a las partes, puesto que, conforme al № $1^{\circ}$ del artículo 194 del Código de Procedimiento Civil. "...se concederá apelación sólo en el efecto devolutivo: $1^{\text {으 }}$ De las resoluciones dictadas contra el demandado en los juicios ejecutivos...", lo que significa que, según el artículo 192 del mismo cuerpo legal "...seguirá el tribunal inferior conociendo de la causa hasta su terminación, inclusa la ejecución de la sentencia definitiva". Sin embargo, existe la norma especial del artículo 475 del tantas veces citado Código de Procedimiento Civil, que al respecto dispone: "Si se interpone apelación de la sentencia de pago, no podrá procederse a la ejecución de esta sentencia, pendiente el recurso, sino en caso que el ejecutante caucione las resultas del mismo".

En fin, sea que no haya habido oposición al cumplimiento de la sentencia o a la acción ejecutiva, o sea que se haya notificado a las partes la sentencia interlocutoria que rechaza la oposición al cumplimiento de la sentencia definitiva del juicio declarativo (salvo que, apelada, el tribunal de alzada dictare orden de no innovar), o sea que la sentencia de pago en el juicio ejecutivo no haya sido objeto de recurso alguno dentro del plazo legal o que, apelada, el ejecutante caucionare las resultas del recurso, en todos estos casos procede aplicar el artículo 481 del Código de Procedimiento Civil, que concretamente ordena "...se procederá a la venta de los bienes embargados, de conformidad a los artículos siguientes".

Los derechos sociales en una sociedad de personas no son "efectos de comercio", calidad que si es posible atribuir a las "acciones", que son los títulos de los derechos societarios de un socio -accionista- de una sociedad anónima o en comandita por acciones. Por consiguiente, no es posible realizar la venta en la forma establecida en el artículo 484 del citado Código de Procedimiento Civil, puesto que ella es privativa exclusivamente para "los efectos de comercio realizables en el acto". Tampoco es 
aplicable al caso en estudio la forma de venta establecida en el artículo 483 del mismo Código, puesto que los derechos de un socio en una sociedad de personas, aunque constituyen un bien mueble, es evidente que no están "sujetos a corrupción o susceptibles de próximo deterioro, o cuya conservación sea difícil o muy dispendiosa".

Veamos, entonces, si es posible vender esos derechos sociales, que constituyen un bien mueble, en la forma previstas en el artículo 482 del Código de Procedimiento Civil, que dispone: "Los bienes muebles embargados se venderán en martillo, siempre que sea posible, sin necesidad de tasación. La venta se hará por el martillero designado por el tribunal que corresponda". A primera vista pareciera que ésta sería la forma de venta, pero no podemos soslayar la frase intercalada por el legislador: "siempre que sea posible". Y, lamentablemente, ello resulta imposible por la definición que el artículo $1^{\circ}$ de la ley 18.118, (sobre el ejercicio de la actividad de martillero público), da respecto de este comisionista para vender, que es la siguiente: "Son martilleros las personas naturales o jurídicas inscritas en un registro, en conformidad a esta ley, para vender públicamente al mejor postor toda clase de bienes corporales muebles". En consecuencia, siendo los derechos de un socio en la sociedad un bien incorporal mueble, (Arts. 576 y 578 del Código Civil), no puede entregarse su venta a un martillero.

Por ende, nos queda solamente la forma residual de venta que el artículo 485 del Código de Procedimiento Civil establece en los siguientes términos: "Los demás bienes no comprendidos en los tres artículos anteriores, se tasarán y venderán en remate público ante el tribunal que conoce de la ejecución, o ante el tribunal dentro de cuya jurisdicción estén situados los bienes, cuando así se resuelva a solicitud de parte y por motivos fundados".

La tasación deberá practicarse por peritos nombrados en la forma que dispone el artículo 414; los incisos segundo y siguientes del artículo 486 y el artículo 487, todos del Código de Procedimiento Civil. Salvo convenio expreso de las partes, no se admitirá postura que baje de los dos tercios de la tasación. Todo postor, para tomar parte en la subasta, deberá rendir caución suficiente, calificada por el tribunal sin ulterior recurso, y será equivalente al diez por ciento de la valorización aprobada. El precio de los derechos rematados deberá pagarse de contado, salvo que las partes acuerden o que el tribunal, por motivos fundados, resuelva otra cosa. Las demás condiciones para la subasta se propondrán por el ejecutante, con citación de la contraria, y la eventual oposición que se formulare será resuelta de plano por el tribunal, consultando la mayor facilidad y el mejor resultado de la enajenación. Aprobada la tasación, se señalará día y hora para la subasta.

La venta de los derechos sociales del deudor, con el señalamiento del día y hora en que deberá tener lugar la subasta, se anunciará por medio de avisos publicados, a lo menos por cuatro veces, en un diario de la comuna o de la capital de la región, si en 
aquélla no lo hubiere, pudiendo publicarse en días inhábiles, el primero de los cuales deberá ser publicado con quince días corridos de anticipación, como mínimo, a la fecha de la subasta.

Debemos recordar aquí lo ya expuesto anteriormente: "Antes de verificarse el remate, puede el deudor libertar sus bienes pagando la deuda y las costas". (Art. 490 del Código de Procedimiento Civil). Facultad que puede ejercer cualquier tercero distinto del deudor, incluyendo sus consocios o la sociedad, los que se subrogarían en los derechos del acreedor.

Si no se presentaren postores en el día señalado para la subasta, el acreedor podrá solicitar a su arbitrio: $1^{\circ}$, que se le adjudiquen los derechos sociales del deudor por los dos tercios de su tasación, ó $2^{\circ}$, que se reduzca prudencialmente el avalúo aprobado, reducción que no podrá exceder de una tercera parte del valor tasado, y que se saquen nuevamente a venta en remate público. Si nuevamente no se presentaren postores entonces tendrá las siguientes opciones: $1^{a}$, que se le adjudiquen los derechos sociales por los dichos dos tercios; $2^{\mathrm{a}}$, que se pongan por tercera vez a remate, por el precio que el tribunal designe y $3^{a}$, que se le entreguen los derechos sociales en prenda pretoria. En este último caso, (entrega en prenda pretoria), el deudor podría solicitar que se pongan los derechos sociales por última vez a remate, sin mínimo para las posturas.

Del remate se levantará acta en el registro especial que lleva el secretario del tribunal, que firmarán el juez, el rematante (que sabemos puede serlo el propio acreedor), y el secretario, agregándose al proceso un extracto del acta. Dentro de tercero día de celebrado el remate, (o un plazo mayor si así se hubiere establecido en las bases), se otorgará la escritura definitiva, con inserción de los antecedentes necesarios, (ver inciso segundo del artículo 410 del Código Orgánico de Tribunales), con los demás requisitos, la que será suscrita por el rematante y por el juez, como representante legal del vendedor, y se entenderá autorizado el rematante para requerir y firmar por sí solo la inscripción en el Conservador, aun sin mención expresa de esta facultad. Obviamente que si la sociedad fuere de aquéllas que requieren tal solemnidad, junto con la autorización de la escritura pública, el notario emitirá un extracto de la misma para su inscripción y publicación oportunas.

Cabe, por último, recordar que, conforme al inciso tercero del artículo 671 del Código Civil, "en las ventas forzadas que se hacen por decreto judicial a petición de un acreedor, en pública subasta, la persona cuyo dominio se transfiere es el tradente, y el juez su representante legal". 


\section{VII.- EFECTOS DE LA ENAJENACION JUDICIAL DE LOS DERECHOS SOCIALES.}

Esta fase del proceso de embargo y realización de los derechos sociales de un deudor, socio de una sociedad de personas, es la que ha llevado a algunos autores Gabriel Palma, Arturo Alessandri y Manuel Somarriva entre otros - a afirmar su inembargabilidad atendida la característica de contrato "intuito personae" que tienen esas sociedades. La intromisión de un socio no considerado al celebrar el contrato de sociedad, aunque sea por el ministerio de la justicia, atentaría contra la naturaleza de dicho contrato, por lo que concluyen que ello no sería factible $y$, por ende, que los derechos de ningún socio podrían ser embargados por un acreedor personal de dicho socio, evitándose así la posibilidad de tal intromisión.

Ya se transcribieron, en el acápite IV de este ensayo, los argumentos dados por el profesor Munita para concluir la embargabilidad de esos derechos sociales y, consecuentemente, la posibilidad de su enajenación judicial. Pretendemos ahora exponer los efectos que, a nuestro parecer, produciría la enajenación judicial de esos derechos, tanto respecto del acreedor personal del socio, como especialmente respecto del socio deudor, el rematante y la sociedad o los demás socios.

A.- Respecto del acreedor.- Al hablar en el acápite precedente sobre la realización de los derechos sociales embargados, vimos que el acreedor personal del socio podía en determinadas circunstancias, solicitar que se le adjudicaran a él dichos derechos por los dos tercios de su valorización. Como los efectos en este caso son similares a los de cualquier otro subastador que rematare dichos derechos, nos referiremos a ellos conjuntamente. En todo caso, si el valor de la adjudicación cubre todo o parte de la deuda, este acreedor quedará satisfecho en la totalidad de su crédito o en la parte que alcance a cubrir el valor de la adjudicación. Si el valor de la deuda, incluyendo intereses y costas, fuere inferior al valor de la adjudicación, deberá consignar la diferencia, a la que tendrá derecho el deudor ejecutado.

Si el rematante fuere un tercero, éste deberá consignar el precio del remate en la cuenta corriente del tribunal, el que, previa liquidación del crédito y tasación y regulación de costas, librará el cheque correspondiente a favor del acreedor. Y si quedare algún saldo, después de pagar al acreedor, ese dinero quedará a disposición del deudor ejecutado.

B.- Respecto del socio deudor.- Evidentemente que el deudor cuyos derechos sociales han sido enajenados, por el ministerio de la justicia, queda privado de todos sus derechos en la sociedad y sólo le quedaría percibir el saldo del precio del remate, si lo hubiere después de haberse pagado al acreedor la totalidad de su crédito, considerados el capital, intereses y costas. 
Sin embargo, surge una dificultad en la determinación de dicho efecto para el evento de que el deudor, además de ser socio, fuere el o uno de los administradores de la sociedad. En las sociedades en comandita me parece que la calidad de socio gestor lleva aparejada la responsabilidad de la administración y viceversa. Algo similar ocurre con las sociedades colectivas y de responsabilidad limitada civiles, en las que, conforme a las normas del Párrafo 4 del Título XXVIII del Libro IV del Código Civil - artículos 2.071 al 2.081 -, parece que la administración sólo podrían ejercerla los socios. En estos casos, la pérdida de la calidad de socio también implicaría la de administrador.

Distinto es el caso de las sociedades colectivas y de responsabilidad limitada comerciales, puesto que, conforme al artículo 385 del Código de Comercio, los socios pueden desempeñar la administración por sí mismos o "por sus delegados, sean socios o extraños". En el caso que se hubiera delegado la administración en el socio ejecutado, estimo que la pérdida de su calidad de socio no lo inhabilitaría para seguir ejerciendo la administración, puesto que ella puede estar delegada en un "extraño" a la sociedad; salvo, obviamente, que los socios le retiren formalmente tal delegación administrativa.

C.- Respecto del rematante.- Incluimos aqui también los efectos de la enajenación respecto del acreedor, cuando éste haya sido el adjudicatario de los derechos sociales embargados a su deudor, porque también se hace dueño de dichos derechos, mediante su tradición, al igual que el rematante. Puede también haber participado en la subasta y adquirido en el remate los derechos sociales del deudor alguno o algunos de sus consocios, e incluso creo que puede hacerlo la misma sociedad, persona jurídica distinta de los socios individualmente considerados, puesto que no parece que existieran en las sociedades de personas las limitaciones para adquirir y poseer acciones de su propia emisión establecidas en el artículo 27 de la ley 18.046 para las sociedades anónimas.

Pues bien, el efecto de la enajenación de los derechos sociales en remate judicial, convierte al rematante en dueño de esos derechos; ocuparía el lugar del deudor en la sociedad, sucediéndolo en todos sus derechos y obligaciones transferibles. Debe tenerse en cuenta al respecto que, salvo el caso de las sociedades de responsabilidad limitada, el nuevo socio pasaría a responder ilimitadamente con su patrimonio de las obligaciones contraídas en interés de la sociedad, y en algunos casos solidariamente. Obviamente que esa responsabilidad correspondería a las obligaciones derivadas de los actos y contratos celebrados con posterioridad a su incorporación como socio.

D.- Respecto de los socios y la sociedad.- En primer lugar hay que aclarar que si el rematante fuere el único consocio del deudor, la sociedad se disuelve, puesto que es de la esencia de una sociedad, tal como lo señala su definición del artículo 2.053 del Código Civil, que esté conformada por "dos o más personas". Similar criterio habría que aplicar si la rematante fuere la misma sociedad, "persona jurídica distinta de los 
socios individualmente considerados", si con la salida del socio deudor quedare uno solo. La adquisición de los derechos sociales del deudor por la misma sociedad afecta a la efectividad del capital social y, en su oportunidad, a la distribución de ganancias y pérdidas entre los demás socios subsistentes, pero no puede convertir a la sociedad en socia de sí misma, puesto que alteraría la esencia misma de la sociedad que, según hemos repetido majaderamente, es "una persona jurídica distinta de los socios individualmente considerados". Entonces, si de los socios que la componen quedare uno solo, la sociedad se disuelve al no estar integrada por "dos o más personas" distintas de la sociedad misma.

En los demás casos, debe atenerse primeramente a la autonomía de la voluntad. El o los socios preexistentes y el rematante podrían convenir lo que estimaren más adecuado a sus intereses, incluso el admitir como nuevo socio al rematante y continuar la sociedad con él. Podrían estipular todos ellos la continuación de la sociedad sin el rematante, aplicando entonces por analogía lo dispuesto en el inciso primero del artículo 2.105 del Código Civil - relativo a los herederos del socio difunto que no hubieren de entrar en la sociedad que deba continuar tras su muerte - que resuelve el problema en los siguientes términos: "Los herederos del socio difunto (el rematante), que no hayan de entrar en sociedad con los sobrevivientes (preexistentes), no podrán reclamar sino lo que tocare a su autor, según el estado de los negocios sociales al tiempo de saberse la muerte (el remate); y no participarán de los emolumentos o pérdidas posteriores sino cuanto fueren consecuencia de las operaciones que al tiempo de saberse la muerte (el remate) estaban ya iniciadas". También podrían convenir entre todos ellos que el rematante les vendiera los derechos sociales adquiridos en el remate, a uno o varios de los socios preexistentes, estipulando precio, plazos, condiciones, modos, etcétera. En fin, podrían celebrar todo tipo de contrato o convención que no sea contrario a la esencia de la sociedad, que no esté expresamente prohibido por las leyes, ni sea contrario a la moral, las buenas costumbres o al orden público.

Si no lograren llegar a un acuerdo sobre el tema, tratándose de una sociedad de personas, podría aplicarse lo dispuesto en el inciso primero del artículo 2.108 del Código Civil, que dice: "La sociedad puede expirar también por la renuncia de uno de los socios". Esta no es una causal de disolución de la sociedad que opere de pleno derecho, sino que es facultativa ("puede") de cualquiera de los socios. También podría objetarse que no correspondería a la pérdida de la calidad de socio como consecuencia del remate, puesto que la renuncia involucraría la voluntad expresa del socio de retirarse. Sin embargo, al respecto la ley señala expresamente, en el artículo 2.113 del Código Civil, que: "Las disposiciones de los artículos precedentes comprenden al socio que de hecho se retira de la sociedad sin renuncia". Entonces, retirado de hecho el socio deudor, por haberse rematado sus derechos sociales por el ministerio de la justicia, cualquiera de sus consocios puede provocar la disolución de la sociedad y posterior 
liquidación, en forma subsidiaria de un eventual acuerdo de voluntades sobre la subsistencia de la misma con o sin la participación del rematante.

\section{COROLARIOS}

A.- La "inembargabilidad" de un bien es de derecho estricto. Por ende, no existiendo ninguna disposición legal expresa que la establezca, los derechos sociales en una sociedad de personas son embargables por el acreedor personal del socio. Este derecho a embargar los derechos sociales del deudor, es distinto del que tiene el mismo acreedor para solicitar la retención de la parte de interés en la sociedad que su deudor tuviere para percibirla al tiempo de la división social (Art. 380 inc. $1^{\circ}$ del Código de Comercio), y del que tiene para pedir que se embarguen a su favor las asignaciones que se hagan a su deudor por cuenta de los beneficios sociales o de sus aportes o acciones (Art. 2.096 inc. 32 del Código Civil).

B.- Siendo los derechos sociales en una sociedad de personas bienes "incorporales" muebles, su realización judicial deberá verificarse en la forma prevista en los artículos 485 y siguientes del Código de Procedimiento Civil, esto es: "se tasarán y venderán en remate público ante el tribunal que conoce de la ejecución".

C.- Verificado el remate y efectuada la tradición de los derechos sociales, conforme a las normas legales pertinentes, el deudor pierde su calidad de socio, sucediéndole en todos sus derechos y obligaciones como tal el rematante o adjudicatario.

El acreedor se pagará, total o parcialmente, con el precio del remate o el valor en que se le hubieren adjudicado los derechos sociales del deudor.

Si por efecto del remate y tradición de los derechos del deudor quedare como socio una sola persona, distinta de la sociedad, ésta deberá disolverse, por ser de la esencia de ella que la compongan dos o más personas distintas de la persona jurídica sociedad.

En los demás casos, el o los consocios preexistentes podrán convenir con el nuevo socio, rematante o adjudicatario de los derechos sociales del deudor, todo aquello que estimaren conveniente a sus intereses, como ser: continuar la sociedad con el nuevo socio; continuar sin el nuevo socio, pagándole lo que le correspondiere según el estado de los negocios sociales al tiempo de saberse la ejecución del remate; comprarle al rematante los derechos sociales que adquirió mediante el remate y tradición, o, en general, cualquier otro pacto que estimaren convenirles. 
Si no hubiere acuerdo, cualquiera de los socios podrá provocar la disolución de la sociedad, puesto que, tratándose de un contrato "intuito personae", los artículos 2.108 y 2.113 del Código Civil establecen como causal de disolución voluntaria la circunstancia del "socio que de hecho se retira de la sociedad sin renuncia", lo que ocurre cuando, por el ministerio de la justicia, se enajenan sus derechos en remate público ante el tribunal de la causa. Como consecuencia de esta disolución, deberá procederse a la liquidación de la sociedad y entregar a cada uno de los socios - incluido el incorporado por efectos del remate y tradición de los derechos sociales del deudor lo que correspondiere en el haber social. 